\title{
ENGLISH AS A FOREIGN LANGUAGE (EFL) INSTRUCTION FOCUSED ON INTELLIGIBILITY OF PRONUNCIATION IN SECONDARY EDUCATION
}

\author{
Reiko Yamamoto ${ }^{1}$ \\ ${ }^{1}$ Associate Professor, Department of English Studies for Careers, Kyoto Junior College of Foreign Languages, Kyoto, \\ Japan
}

\begin{abstract}
This paper describes a research project that focuses on the intelligibility of pronunciation in English as a foreign language (EFL) learners. English could be called a lingua franca, or a language that makes communication possible between people who do not share a native language. In the globalized world, English need not be pronounced correctly, but can be pronounced with any accent as long as it is intelligible. The fact that Japanese speakers' English generally lacks intelligibility is attributed to the difference between Japanese and English. The aim of this study is to devise explicit instruction on the difference of the two languages in the phonetic system and the relation between letters and sounds. This experiment was executed in two junior high schools, with one as the treatment group and the other as the contrast group. The seventh-grade students in the treatment group were given instruction in the rules of phonics and the international phonetic alphabet (IPA), while the seventh-grade students in the contrast group were given normal instruction on pronunciation. The pronunciation test was administered in both groups before and after the year-long instruction. The recoded data from the test was assessed by a native English speaker with criteria of intelligibility. The results of the pre-and post-test proved that the treatment group exceeded the contrast group with a significant difference. It is anticipated that phonics and IPA instruction at the beginning of EFL learning would lay the foundations for students' development into English speakers who can pass in globalized society.
\end{abstract}

Keywords: English as a foreign language (EFL), secondary education, intelligibility, pronunciation, International Phonetic Alphabet (IPA)

\section{INTRODUCTION}

English could be called a lingua franca, or a language that makes communication possible between people who do not share a native language. In the globalized world, English need not be pronounced correctly, but can be pronounced with any accent as long as it is intelligible. The more globalized the world becomes, the more non-Englishspeaking countries focus on boosting international competitiveness based on English proficiency. Economic development in Asia especially promoted reform in EFL education. Asian countries, except for some that experienced the colonial era, had no history of plurilingual education. However, many countries introduced EFL education to younger students in the 1990s. [1]surveyed the approximate time when EFL was assigned as a subject in elementary school: in Thailand in 1996; in Vietnam in 1996; in Korea in 1997; in China in 2001; in Taiwan in 2001. Japan was left behind, despite indications that Japanese are poor in English communication and that English with a Japanese accent is unintelligible.

In 2011, the Ministry of Education, Culture, Sports, Science, and Technology (MEXT) in Japan finally introduced English activities for oral communication into fifth and sixth grade classes. Even if English activities were not a subject, this author expected that there was an opportunity to reform
EFL education in Japanese secondary school, where instruction for students has not focused on pronunciation. As expected, it was shown that younger students are eager to imitate unfamiliar sounds and come to pronounce English words correctly. Therefore, has a new phase been ushered in for secondary education? The answer is no. This author has had many chances to observe EFL classes both in elementary school and in junior high school, and has noticed that the pronunciation of many junior high school students gets worse than when they were in elementary school. In these old-fashioned classes based on lectures, junior high school students' entire attention is put on form and grammar, not on sounds. As things are today, secondary education has failed to follow up on the successes of elementary school education. Compared to younger students, junior high school students are not interested in listening to or imitating unfamiliar sounds. Teachers have no idea how to instruct pronunciation. It is necessary to develop an effective methodology for instructing pronunciation in secondary education.

\section{LITERATURE REVIEW}

\subsection{Syllables}

In analyzing the difference between Japanese sound and that of English, syllables come first. Japanese language has a 
system of open syllables[2]. The shortest unit of English sound is a phoneme, while that of Japanese is a mora. That is why Japanese native speakers are apt to insert vowels between consonants or add a vowel after the last consonant of an English word. For instance, "apple" has become a loanword in Japanese, and the sound is /apuru/. "Apple" is counted as two syllables, while /a/ /pu/ / ru/ is counted as three moras. Word accent does not exist in Japanese words, including in loanwords from English. Needless to say, word accent plays a significant role in intelligibility.

\subsection{Prosody}

Prosody also plays a significant role in intelligibility. English has stressed syllables, which enable a sentence to keep an equal space between each accent as follows: Nice to meet you, too. (each of the three bold words has a stressed syllable.) Rise and fall of pitch in a sentence introduces intonation. Intonation has the function of expressing feeling, emotions, attitudes, and discourse information of a speaker [2]. [2] calls an utterance with the right prosody "Englishlike." Japanese accent lacks "English-like" sounds. It makes their pronunciation unintelligible for English native speakers.

\subsection{Katakana Method}

The Japanese history should be referred before discussing the unique katakana method; Japan went through a period of national isolation policy in the Edo period (1600-1868). Therefore, Japanese people had little chance to learn foreign languages until the end of the period. When they started to learn foreign languages, it was reasonable for them to utilize katakana to transliterate foreign languages, because they had never seen roman letters. Katakana is the square form of kana, Japanese letters. Katakana, the form of syllabic Japanese writing, typically used for words adopted from other languages. Japanese people have transliterated English words in katakana since the end of the Edo period. Katakana letters that show the sound of “milk" are, for instance, “ミル ク."The Japanese syllabary consists of 50 mora sounds (one mora is a set of a consonant and a vowel). As a matter of course, katakana consists of 50 letters and milk is changed into three katakana letters that stand for $/ \mathrm{mi} / / \mathrm{ru} / / \mathrm{ku} /$. Also, Katakana method is perceived in an EFL education in Japan as a bad tradition. [3]point out that katakana is used even in beginners' English-Japanese dictionaries and guidebooks for junior high school textbooks authorized by the MEXT. It is often seen in EFL class in junior high school that teachers write katakana on the board or worksheet and make their students use katakana to memorize English pronunciation. In short, using katakana is a normal way to teach English pronunciation in junior high schools in Japan. This might be because the international phonetic alphabet (IPA) is judged to be too difficult for junior high school students. By its very nature, students will never master "English-like" sound later in high schools or universities. They have difficulties in distinguish / $\mathrm{r} /$ sound from /1/ sound, or /a/ sound from $/ \Lambda$ / sound, because they can pronounce only the sounds which exist in Japanese. [3] are opposed to using katakana and insist that students are capable of acquiring the IPA and acquiring pronunciation that is acceptable for native English speakers.

\subsection{The International Phonetic Alphabet (IPA)}

The IPA is a system of phonetic notation which was devised to represent sounds - phones or phonemes - used in spoken human languages. It is intended as a notational standard for the phonemic and phonetic representation of all spoken languages, thus it is used not only by learners of English but by learners of various languages such as Germany, French, and so on. The IPA consists of phonetic symbols consolidated by the International Phonetic Association. The IPA has been modified into simpler signs in Japan. Table 1 shows the simpler version of IPA for vowels, which has been mainly used in Japanese dictionaries for English learners [4].

Table -1: The Simple Version of IPA for Vowels Used in Japan

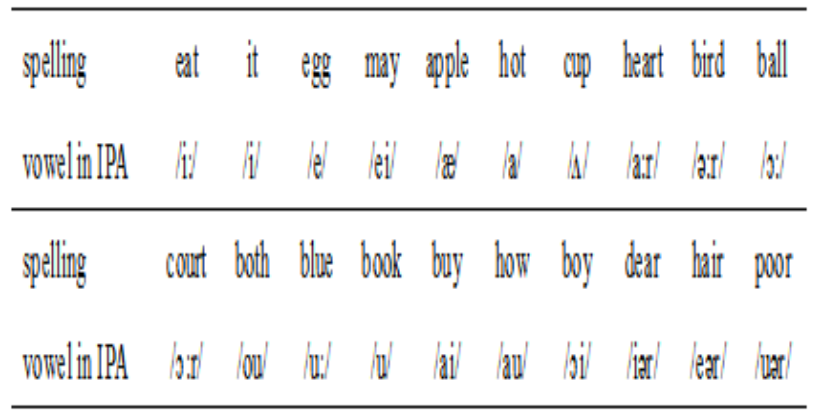

The IPA for the vowels shown in Table 1 is the simplest version in various dictionaries. Some dictionaries include more signs like /I/. Japanese has an /i/ sound but not an /I/ sound. Therefore, it is hard for the Japanese to identify /I/ and /i/. Moreover, it does not lead to serious misunderstanding if one pronounces "it" not as /It/ but as /it/. By these two reasons, /I/ and /i/ are integrated into /i/ in Table 1. It is not necessary to narrow the transcription in the IPA used in dictionaries for English learners. This is because using dictionaries with complicated signs might deviate from learners' goal to acquire English [4]. The IPA was modified into simpler signs for consonants as well (Table 2).

Table -2: The Simple Version of IPA for Consonants Used in Japan

\begin{tabular}{|c|c|c|c|c|c|c|c|c|}
\hline spelling & book & $\operatorname{dog}$ & fish & $\operatorname{dog}$ & hat & king & lemon & man \\
\hline consonant in IPA & 16 & Id & $|\theta|$ & $|g|$ & W & k & N & $|\mathrm{m}|$ \\
\hline spelling & net & pen & fing & sin & tree & vidin & wood & 200 \\
\hline consonatit in IPA & $\ln$ & $\mid \mathrm{p}$ & $|t|$ & $1 \mathrm{~s}^{\mathrm{s}}$ & $|t|$ & $|\mathrm{v}|$ & $|w|$ & $z$ \\
\hline spelling & three & this & sing & yacht & ship & cherry & juice & $\cdots$ \\
\hline consonant in IIA & $1 \theta$ & $|0|$ & $|n|$ & |j| & 19) & $|t|$ & (b) & - \\
\hline
\end{tabular}




\subsection{IPA versus Katakana}

As referred above, prosody should give priority to sounds like vowels or consonants in instruction for EFL learners. When students can distinguish each vowel and consonant sound to some extent, teachers can proceed to the next step and instruct students on prosody such as stress or intonation. The IPA has the advantage in this step, because katakana represents segmental phonemes, while the IPA can represent word stress of supra-segmental phonemes besides segmental phonemes [4]. [5]conducted a survey of university students. It was revealed in the survey that the students had had no opportunity to learn how to pronounce English words in EFL class at elementary and junior high schools. What is worse is that the teachers had never learned how to instruct students in English pronunciation in the teacher training course at university. Phonetics is not a mandatory subject for obtaining an EFL teacher's certificate in Japan [6]. Notwithstanding this condition, EFL learners in Japan want to improve their English pronunciation [7]. It is high time that EFL teachers in Japan stop using the katakana method. This study is going to introduce instruction using the IPA and prove its effects on intelligibility through the quantitative data of the pronunciation test score.

\section{HYPOTHESIS}

The hypothesis of this study is that instruction using the IPA instead of katakana effects on intelligibility of junior high school students' English pronunciation. The goal of this study is to verify this hypothesis.

\section{METHODOLOGY}

\subsection{Pilot Test}

A pilot test prior to the experiment in this study revealed that university students are capable of acquiring and utilizing the IPA for pronouncing English words [8]. The participants of the pilot test were 18 university students aged 18 to 21 . None of the student had learned the IPA. They took a class named "Four Skills in English" allotted to one semester from September to January, and each period of the class included a module time of instruction using the IPA (around 15minutes). The pronunciation test using the IPA given at the end of the semester proved that the students' pronunciation improved. When the students heard that they were to learn the IPA at first, some of them showed antipathy. Nevertheless, they said their impression of the IPA had perfectly changed at the end of the semester. Acquiring the IPA is easier than they imagined, and they are sure of their enhancement of English word pronunciation. Most of them wished if they had learned the IPA in junior high school. One of them said, "If had learned the IPA in junior high school, I would have been a better speaker of English." That means that university students judged the IPA to be effective for junior high school students.

\subsection{Participants}

Two junior high schools in Japan took part in this experiment. The participants were 58 seventh-grade students: 29 students from Junior High School A (J.H.A.), and 29 students from Junior High School B (J.H.B.). In J.H.A., the treatment group, the IPA was introduced at the beginning of the semester, associating it with the knowledge of alphabet phonics that the students had acquired in elementary school. The IPA was used whenever they learned new words in textbooks, but the required time never exceeded that of the contrast group. In J.H.B., the contrast group, pronunciation was taught normally through listening, repeating, or reading katakana.

\subsection{Pronunciation Test}

The process of the pre- and post-test was as follows: each student moved to a room next to the classroom one by one, where the author was waiting to give a pronunciation test. In the pre-test, the author showed the student a card on which a picture and the spelling of the word describing the picture were printed (See Fig. 1).

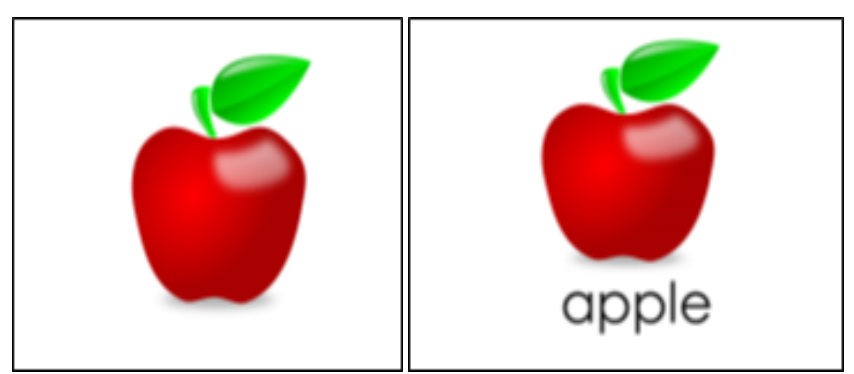

Fig -1: (a) A card with a picture; (b) A card with a picture and the spelling

Next, the author told the student to read the word aloud and showed ten cards one after another: apple, cherry, cake, salad, ball, bird, bus, three, five, box. All the students' readings were recorded by a digital voice recorder.

On the other hand, in the post-test, the author showed each student two kinds of cards; one with a picture and the other with the spelling of the word the same as the pre-test. Besides, the author added another kind of card on which a picture and the IPA of the word were printed (See Fig. 2).

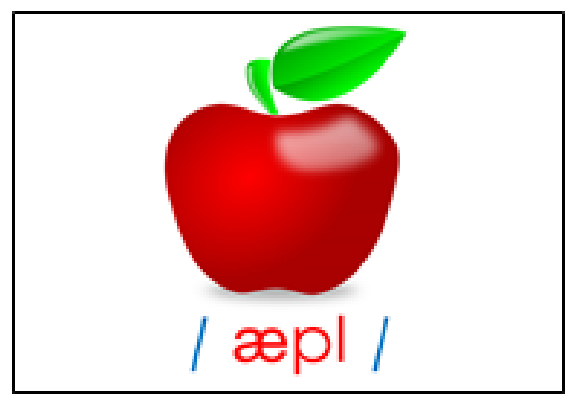

Fig -2: A card with a picture and the IPA of the word

In requesting an English native speaker (an EFL teacher in Japan) to assess the test, the author was careful not to saddle her with too many criteria. The simple criterion was as follows: assess the students using five grades from the perspective of intelligibility (grade one was the lowest, and grade five was the highest). Additionally, for the same 
reason - not to saddle the assessor with too many criteriathe author narrowed the objectives just to words, not idioms or sentences. The literature review had certainly led the author to think that intelligibility results from segmental phonemes like vowels and consonants, and supra-segmental phonemes or prosodies like word accents. The simplified IPA still keeps two things to indicate long vowels /:/ and accent vowels $/{ }^{1} /$, and learners can comprehend prosody in a word such as "banana" /bə ${ }^{1}$ næ nə /. The test covering words can judge both segmental and suprasegmental phases.

In another pilot test conducted just before this experiment, two assessors (A and B) assessed the junior high school students' pronunciation using the same criterion. Both the assessors were native English speakers. The reliability of the test was proved (See Table 3 and Table 4).

Table -3: The Results of the Pilot Test by Two Assessors

\begin{tabular}{cccccc}
\hline & $M$ & $S D$ & $N$ & means of tie scale & dispersion of the scale \\
Assesson A & 3.4190 & 52875 & 174 & 3.0776 & .121 \\
\hline Assessor B & 3.0776 & 34727 & 174 & 3.4190 & .280 \\
\hline
\end{tabular}

Table -4: The Statistic Reliability

\begin{tabular}{|l|l|}
\hline Cronbach $\boldsymbol{\alpha}$ & number of categories \\
\hline .521 & 2 \\
\hline
\end{tabular}

The pre- and post-test of the experiment in this study were assessed by Assessor A, and her assessment can be judged to be reliable.

\subsection{Materials for the IPA Learning}

In order to support EFL teachers who had not learned how to teach the IPA, it was necessary to develop teaching materials. These materials were intended to enable students to learn easily and have fun, motivating them to learn the IPA. Examples of the slides that were projected on the screen in a classroom are shown in Fig. 3.

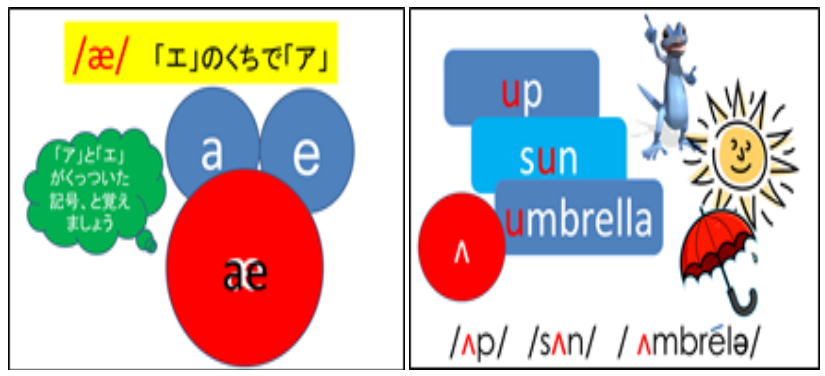

Fig -3: Slides shown to the students in instructing IPA

\subsection{Procedure}

The experiment had four steps:

1) A pronunciation test was given as a pre-test at the beginning of the school year.

2) When new vocabulary was introduced in the class, the students listened to a CD and repeated what they heard.
3) The same pronunciation test was given as a post-test at the end of the school year.

4) A native English speaker assessed the test from the perspective of intelligibility.

The same steps were executed in both schools, with the only difference in Step 2. In J.H.A., the treatment group, the IPA was introduced at the beginning of the semester, which associated it with the knowledge of alphabet phonics that the students had acquired in elementary school. That enabled the teacher of the treatment group to introduce new vocabulary with the IPA.

\subsection{Results}

Each ten-word score was calculated into an average for each student, and the scores of the treatment group and the contrast group were compared and analyzed statistically. The average of each group of the pre-test and the results of the t-test are shown in Table 5.

Table -5: The Results of the Pre-test

\begin{tabular}{lcccccc}
\hline & $M$ & $S D$ & $N$ & $t$ & df & $p$ \\
\hline treatment pictures only & 2.8345 & .39213 & 29 & .617 & 28 & .542 \\
contrast. pictures only & 2.9303 & .87812 & 29 & & & \\
\hline treatment with spelling & 3.0448 & .38784 & 29 & 1.426 & 28 & .165 \\
contrast. with spelling & 3.1793 & .52534 & 29 & & & \\
\hline
\end{tabular}

As shown in Table 5, statistical significance between the two groups was not found in using the cards with pictures only, nor in using the cards with pictures and the spellings. The homogeneity of both matched classes was proven.

The average for each group of the post-test and the results of the t-test is shown in Table 6.

Table -6: The Results of the Post-test

\begin{tabular}{|c|c|c|c|c|c|c|}
\hline & M & $S D$ & $N$ & $t$ & df & $p$ \\
\hline treatment: pictures only & 3.1103 & .28828 & 29 & 3.771 & 28 & .001 \\
\hline contrast. pictures only & 2.8448 & 36507 & 29 & & & \\
\hline treatment: with spelling & 3.2276 & .19253 & 29 & 1.927 & 28 & .064 \\
\hline contrast with soelling & 3.0759 & .42482 & 29 & & & \\
\hline treatment: with IPA & 3.2621 & .26513 & 29 & 2.156 & 28 & .040 \\
\hline contrast with spelling & 3.0759 & .42482 & 29 & & & \\
\hline
\end{tabular}

It might be taken for granted that the scores of the pre-test are lower than those of the post-test, which was given after one-year EFL instruction. However, Chart 1 shows the interesting contrast between the two groups, in spite of the result that no statistically significant difference was found between pre- and post-test. 


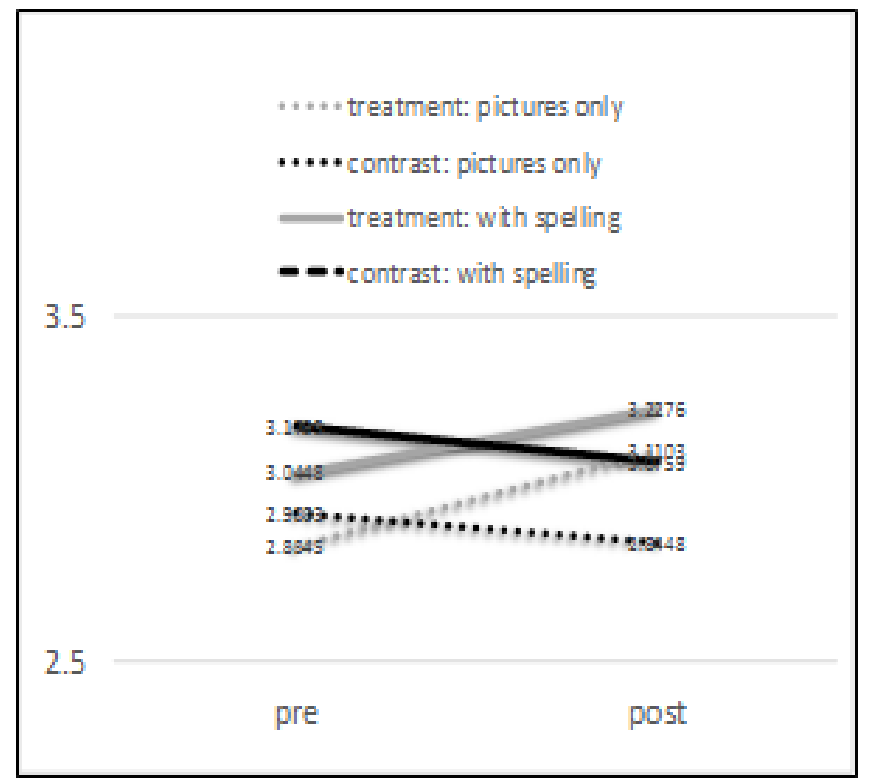

Chart -1: Comparison of pre- and post-test

Comparing the cards with the spellings and the cards with the IPA, the scores were analyzed statistically, and no statistical significance was found (Table 7).

Table -7: Comparison of Two Kinds of the Post-test of the Treatment Group

\begin{tabular}{ccccccc}
\hline & $M$ & $S D$ & $N$ & $t$ & df & $p$ \\
\hline withspellings & 3.2276 & .19253 & 29 & 1.138 & 28 & 265 \\
withthe $\mathbb{P A}$ & 3.2621 & .26513 & 29 & & & \\
\hline
\end{tabular}

\section{FINDINGS}

The hypothesis of this study was that instruction using the IPA instead of katakana affects the intelligibility of junior high school students' English pronunciation. After one-year of instruction using the IPA (without katakana), scores of the post-test improved compared to those of the pre-test in the treatment group, but not significantly. Instead, it was proven that the scores of the treatment group exceeded those of the contrast group when the cards with pictures (without spellings) were used in the post-test. Instruction using the IPA may have contributed to turning students' attention to the syllables and correct sounds of English words even without spellings.

No significant differences were found when the cards with pictures and spellings were used in the post-test, which means that both groups used spellings as scaffolding to pronounce words equally.

Not having learned the IPA, the contrast group did not take the test using the cards with pictures and the IPA. Comparing the scores the treatment group received when the IPA cards were used to those the contrast group received when the spelling cards were used, the treatment group proved to be superior with significant differences. In this test, the students of the treatment group used the IPA as scaffolding to pronounce words, and that was more effective for them than using spellings. To substantiate this claim, the observations during the post-test showed that the students in the treatment group tried to pronounce words by reading the IPA, and that they apparently utilized the knowledge of the IPA.

The results of the statistical analysis of pre- and post-test scores, of which the assessment's criterion is intelligibility, proved the enhancement of the students' pronunciation in the treatment group. This study succeeded in verifying the hypothesis.

\section{CONCLUSION}

The originality of this study is that it focused on the intelligibility of Japanese students' pronunciation and on the differences between Japanese and English in their phonetic systems and the relation between letters and sounds. No previous researchers had noticed the influence of Japanese history and EFL instruction using katakana.

This study explored an alternative method of instruction using the IPA instead of katakana. The experiment revealed that junior high school students were able to acquire the IPA and that the intelligibility of their English pronunciation improved. This suggests that EFL instruction should focus on pronunciation, including prosody, and that utilizing the IPA is an effective way to provide pronunciation instruction.

Moreover, it should be emphasized that the IPA is, so to speak, a means to advance the knowledge of alphabet phonics, which the junior high school students were familiarized with when they were in elementary school. Younger students pay attention to somatic sensation, such as the movement of the mouth or throat to imitate unknown sounds, more than analytic learning such as grammar or forms. They can start analytic learning at any age. As for the somatic sensation, it should be taught at as early stage as possible. That is why university students may feel that if they had learned the IPA in junior high school, they would be better English speakers. From this study, it can be concluded that the instructions at the beginning of EFL learning lay the foundation for students' development into English speakers who can pass in globalized society.

\section{REFERENCES}

[1]. Sashima, T., Sato, S., Iwasaki, S. \& Murata, T. (2015). A Guide to International Studies. Kyoto: Horitsu-bunkasha. [2]. Satoi, H. (2013). The base and practice in English pronunciation. In Y. Ushiro (Eds.), Trends and current issues in English language education in Japan: Integrating theory and practice (pp. 66-69). Tokyo: Japan Society of English Language Education.

[3]. Arimoto, J., \& Kochiyama, M. (2015). Problems of phonetic transcription in guidebooks related to junior high school textbooks authorized by the MEXT. A handout delivered at the National Conference of the Japan Society of English Language Education. 
[4]. Imanaka, M. (2004). Phonetic transcription in instructing phonetic sounds in English (2). Bulletin of Tokyo Seitoku University, 11, 1-11.

[5]. Kochiyama, M., Yamamoto, S., Nakanishi, N., Arimoto, J., \& Yamamoto, K. (2011). A survey on teaching English pronunciation by elementary and junior high school teachers. Japan Association for Language Education and Technology, Kansai Chapter Collected Papers, 13, 57-78.

[6]. Arimoto, J. (2010). The present situation of pronunciation instruction and teachers' disposition. Bulletin of Kansai International University, 8, 33-43.

[7]. Oshima, H., \& Tara, S. (2010). Students' awareness about English pronunciation: From survey at a technical college. Naruto Eigo Kenkyu, 21, 67-78.

[8]. Yamamoto, R. (2017). Effects of EFL instruction utilizing international phonetic alphabet (IPA) on intelligibility of Japanese students. The IAFOR International Conference on Arts \& Humanities - Hawaii 2017 Official Conference Proceedings.

\section{BIOGRAPHIES}

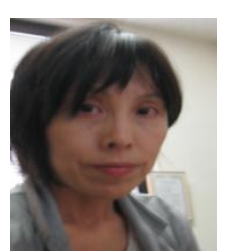

Associate Professor, Department of English Studies for Careers, Kyoto Junior College of Foreign Languages. Have a career as an EFL teacher at elementary school, secondary and high school. 